\title{
Evaluation of white blood cell and neutrophil/lymphocyte ratio in acute coronary syndrome patients admitted to emergency department.
}

\author{
Mustafa Uğur Göktaş', Pınar Yeşim Akyol ${ }^{2 *}$,Zeynep Karakaya ${ }^{2}$, Umut Payza $^{2}$, Fatih Esad Topal ${ }^{2}$ \\ ${ }^{1}$ Department of Emergency, Haseki Training and Research Hospital, Istanbul, Turkey \\ ${ }^{2}$ Department of Emergency Medicine, Izmir Katip Celebi University Ataturk Training and Research Hospital, Izmir, \\ Turkey
}

\begin{abstract}
Objective: Inflammatory reaction, which causes tissue damage in Acute Coronary Syndrome (ACS), leads to deterioration. White Blood Cell (WBC), Neutrophil (N), Lymphocyte (L) and Neutrophil/ Lymphocyte (N/L) ratios were used to refer to the inflammation. High neutrophil levels show us acute inflammatory situation and low lymphocyte levels show us physiological stress. That is why N/L ratio is a valuable parameter which enables us to guess patient prognosis in Emergency Department (ED). In this study, white cell and NLR relations with ACS in patients with chest pain is evaluated.

Material and method: Patients referring to ED with chest pain within 3 months were investigated retrospectively. 100 patients were included in the study. Patients' WBC count, NLR and WBC values, gender, Troponin-I and CK-MB positivity, history of Coronary Heart Disease (CHD) and additional diseases were examined according to the final diagnoses. All the patients were divided into three groups according to ACS: Unstable Angina Pectoris (USAP), Non-ST Elevated Myocardial Infarction (NSTEMI), and ST-Elevated Myocardial Infarction (STEMI). Mortality and morbidity levels in hospital and after discharge were also examined in the study.

Findings: WBC values in patients with positive Troponin-I were found statistically higher than patients with negative Troponin-I $(\mathbf{p}<\mathbf{0 . 0 5})$. In STEMI group, WBC values were statistically higher than USAP group $(\mathbf{p}<\mathbf{0 . 0 0 8 3})$. When patients' $\mathrm{N} / \mathrm{L}$ ratio average distribution was examined; Troponin-I and CK-MB positive patients' NLR was found to be statistically higher than Troponin-I and CK-MB negative ones $(\mathbf{p}<\mathbf{0 . 0 5})$.

Conclusion: N/L ratio, which is a marker of inflammatory process in the myocardial vascular bed, may be considered as a risk marker. For this reason, $\mathrm{N} / \mathrm{L}$ ratio at admission can be used as an auxiliary parameter for predicting the diagnosis of ACS.
\end{abstract}

Keywords: Chest pain, Neutrophil/lymphocyte ratio, Emergency medicine.

Accepted on February 27, 2018

\section{Introduction}

Coronary Artery Disease (CAD) is one of the main causes of premature death among adults. Cardiovascular diseases are responsible for $49 \%$ of all deaths in Europe [1].

Acute Coronary Syndrome (ACS) is associated with many hereditary and acquired risk factors. White blood cell, neutrophil, and lymphocyte counts and NeutrophilLymphocyte Count Ratio (NLR) are markers of systemic inflammation. White blood cell and its subtypes, which are major inflammatory cells, are responsible for adverse events in cardiovascular diseases and are used as a marker of inflammatory conditions. Leukocytes play a crucial role in the inflammatory process. In patients with or without CAD, white blood cell and its subtypes were studied as an inflammatory biomarker in predicting cardiovascular outcomes [2-4].
Today, N/L ratio is accepted as a parameter that combined shows the adverse effects of both high neutrophil levels, which reflect acute inflammation, and low lymphocyte levels, which reflect physiological stress [5]. The inflammatory reaction does not only show a response to tissue damage in ACS, but also leads to a poor clinical course [6,7].

In this study, the relationship between $\mathrm{N} / \mathrm{L}$ ratio, $\mathrm{WBC}$ and ACS was evaluated in patients referring to emergency department with chest pain.

\section{Materials and Methods}

This study included 100 patients aged 18 y and over who were admitted to emergency department with chest pain between July 2015 and November 2015 and who were followed with the preliminary diagnosis of ACS and who did not have 
exclusion criteria. Due to the retrospective design of the study, approval from the local ethics committee was not obtained; however principles outlined by the Declaration of Helsinki were strictly followed. Patients who had clinically active infection, who had active malignancy, who had various hematologic proliferative disorders, who had an active or chronic autoimmune disease, who received steroids or chemotherapy, and who had a history of trauma or surgery within 10 days prior to admission were not included in the study. Non-Cardiac Chest Pain (NCCP) is defined by recurrent episodes of sub sternal chest pain in patients lacking a cardiac cause after a comprehensive evaluation. The data were obtained from the patients' files and the hospital computer registry system.

The age, gender, WBC count, N/L ratio, and presence of additional diseases (Hypertension (HT), Diabetes Mellitus (DM), dyslipidemia (HL), Congestive Heart Failure (CHF), Chronic Renal Failure (CRF), Chronic Obstructive Pulmonary Disease, asthma, and history of CAD (MI, CAG, CABG)) were recorded for all patients included in the study. HT cases were defined as those who had been previously diagnosed and were taking antihypertensive agents. DM cases were defined as those who were taking oral anti-diabetic drugs and insulin. HL cases were defined as those who were taking lipid-lowering therapy. CRF cases were defined as those who were on chronic dialysis program or who were taking anti-acidosis agents and medications affecting potassium homeostasis due to low clearance. All the patients were divided into three groups according to ACS: Unstable Angina Pectoris (USAP), Non-ST Elevated Myocardial Infarction (NSTEMI), and ST-Elevated Myocardial Infarction (STEMI). ACS was defined as having ECG (electrocardiogram) changes and/or elevated cardiac enzyme levels together with a chest pain associated with myocardial ischemia. When patients with STEMI apply to emergency department with chest pain or equivalents, ECG findings may be observed as follows in accordance with ACC/ESC criteria:

- New ST elevation at the $J$ point in two contiguous leads of $>0.1 \mathrm{mV}$ in all leads other than leads V2-V3.

- In leads V2-V3:

(i) $>0.2 \mathrm{mV}$ in men $>40 \mathrm{y}$,

(ii) $>0.25 \mathrm{mV}$ in men $<40 \mathrm{y}$ (or)

(iii) $>0.15 \mathrm{mV}$ in women

- Patients are considered as STEMI if they have high levels of troponin and CK-MB, which are biochemical markers of cardiac necrosis, with new left bundle branch block.

White blood cell, neutrophil, and lymphocyte counts and levels of cardiac markers (troponin/CKMB) obtained from the first venous blood sample on admission to emergency department were recorded as laboratory findings. Differential white blood cell counts were obtained with the Automatic Coulter Counter Method (Coulter LH 780 Hematology Analyzer, Beckman Coulter Corp., Hialeah, Florida).
The N/L ratios were classified into 3 groups: low $(<3.0)$, moderate (3.0-4.7), and high (>4.7).

The average distribution of N/L ratios and WBC counts was examined according to gender, troponin-I and CK-MB positivity, history of $\mathrm{CAD}$, presence of additional diseases, and definitive diagnosis.

\section{Statistical analysis}

Statistical analysis was performed using the IBM SPSS Statics Version 22 package program. The Independent Samples t-test was used to compare the ages of male and female subjects. The Chi-Square and Fisher's exact tests were used to compare categorical data between groups. The Mann-Whitney U-test was used for comparing two groups because continuous data did not show a normal distribution. The Kruskal-Wallis test (a Bonferroni-corrected Mann-Whitney U-test) was used for comparing more than two groups. $\mathrm{p}<0.05$ was considered statistically significant.

\section{Results}

100 patients who were admitted to emergency department within the last 3 months were included in this cross-sectional retrospective study. Of the patients included in the study, $70 \%$ $(n=70)$ were male and $30 \%(n=30)$ were female. There was no statistically significant difference between the male and female subjects in terms of mean age $(\mathrm{p}>0.05)$. The mean age was $57.8 \pm 12.8$ (mean-max: 29-84) y; men $56.2 \pm 11.7$ (mean-max: 29-81) y, women $61.5 \pm 14.7$ (mean-max: 33-84) $(\mathrm{p}>0.05)$.

Of the 100 patients, 66\% $(\mathrm{n}=66)$ had ACS (USAP, NSTEMI, STEMI), 44\% $(n=44)$ had NCCP.

When the average distribution of WBC counts in the patients was examined, WBC count was found to be higher in the patients with positive troponin-I than in the patients with negative troponin-I $(\mathrm{p}<0.05)$ (Table 1$)$.

Table 1. The average distribution of WBC counts according to gender, troponin-I and $C K-M B$ positivity, history of $C A D$, presence of additional disease, and definitive diagnosis.

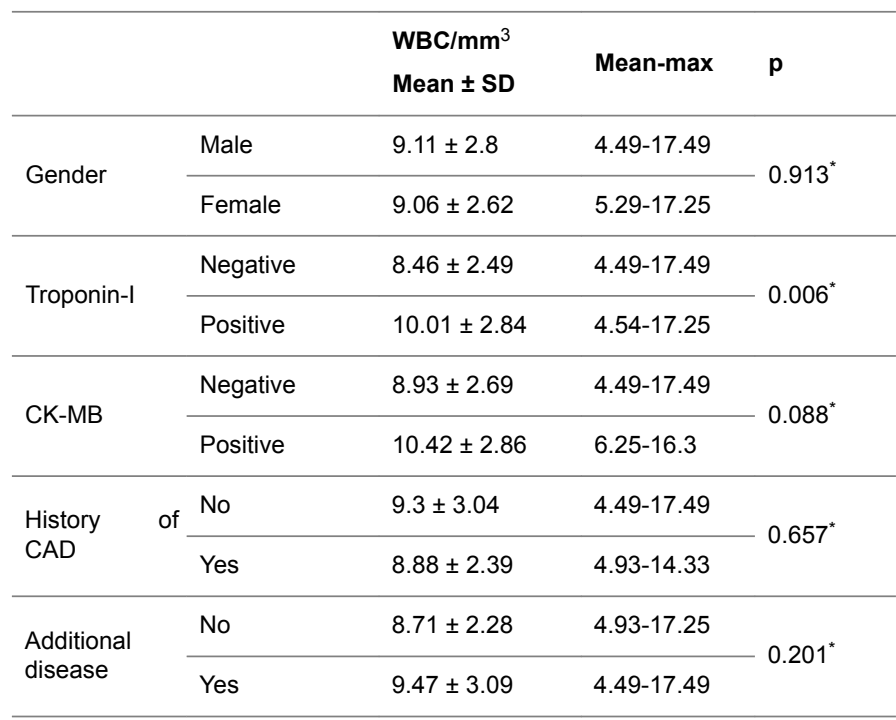


Evaluation of white blood cell and neutrophil/lymphocyte ratio in acute coronary syndrome patients admitted to emergency department

\begin{tabular}{llll}
\hline & Non-cardiac & $8.84 \pm 2.71$ & $4.49-17.49$ \\
\cline { 2 - 4 } $\begin{array}{l}\text { Definitive } \\
\text { diagnosis }\end{array}$ & NSTEMI & $9.29 \pm 2.77$ & $4.54-17.25$ \\
\cline { 2 - 4 } & STEMI & $10.53 \pm 2.72$ & $6.25-16.3$ \\
\cline { 2 - 4 } & USAP & $7.78 \pm 2.13$ & $4.93-12.82$ \\
\hline
\end{tabular}

*Mann-Whitney U test; " Kruskal-Wallis test.

Table 2. The average distribution of N/L ratios according to gender, troponin-I and $C K-M B$ positivity, history of $C A D$, presence of additional disease, and definitive diagnosis.

\begin{tabular}{|c|c|c|c|c|}
\hline & & $\begin{array}{l}\text { WBC } / \mathrm{mm}^{3} \\
\text { Mean } \pm \mathrm{SD}\end{array}$ & Mean-max & $\mathbf{p}$ \\
\hline \multirow{2}{*}{ Gender } & Male & $3.63 \pm 4.53$ & $0.69-31.06$ & \multirow{2}{*}{$0.532^{*}$} \\
\hline & Female & $4.22 \pm 3.86$ & $0.99-15.16$ & \\
\hline \multirow{2}{*}{ Troponin-I } & Negative & $3.06 \pm 4.3$ & $0.69-31.06$ & \multirow{2}{*}{$0.002^{*}$} \\
\hline & Positive & $4.89 \pm 4.19$ & $0.9-19.35$ & \\
\hline \multirow{2}{*}{ CK-MB } & Negative & $3.55 \pm 4.31$ & $0.69-31.06$ & \multirow{2}{*}{$0.010^{*}$} \\
\hline & Positive & $5.86 \pm 4.11$ & $1.16-15.41$ & \\
\hline \multirow{2}{*}{ History of CAD } & No & $3.73 \pm 4.99$ & $0.82-31.06$ & \multirow{2}{*}{$0.268^{*}$} \\
\hline & Yes & $3.89 \pm 3.56$ & $0.69-15.41$ & \\
\hline \multirow{2}{*}{ Additional disease } & No & $2.96 \pm 2.09$ & $0.82-10.69$ & \multirow{2}{*}{$0.542^{*}$} \\
\hline & Yes & $4.63 \pm 5.62$ & $0.69-31.06$ & \\
\hline \multirow{3}{*}{ Definitive diagnosis } & Non-cardiac & $3.84 \pm 5.52$ & $0.9-31.06$ & \multirow{3}{*}{$0.019^{* *}$} \\
\hline & NSTEMI & $4.1 \pm 2.93$ & $0.9-10.69$ & \\
\hline & STEMI & $5.13 \pm 5.17$ & $1.16-19.35$ & \\
\hline
\end{tabular}

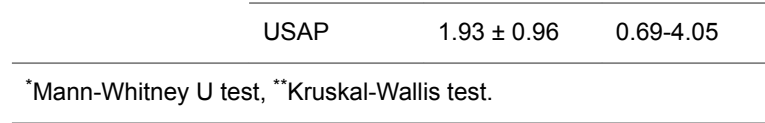

Table 3. The distribution of rates of troponin-I positivity according to N/L ratios.

\begin{tabular}{|c|c|c|c|c|c|c|c|c|}
\hline & & \multicolumn{4}{|c|}{ Troponin-I } & \multicolumn{2}{|c|}{ Total } & \multirow{2}{*}{ p } \\
\hline & & \multicolumn{2}{|c|}{ Negative } & \multicolumn{2}{|c|}{ Positive } & \multirow[b]{2}{*}{$\mathbf{n}$} & \multirow[b]{2}{*}{$\%$} & \\
\hline & & $\mathrm{n}$ & $\%$ & $\mathrm{n}$ & $\%$ & & & \multirow{4}{*}{0.001} \\
\hline \multirow{3}{*}{$\mathrm{N} / \mathrm{L}$ ratio } & Low $(<3.0)$ & 44 & 69.8 & 19 & 30.2 & 63 & 63 & \\
\hline & Moderate (3.0-4.7) & 11 & 73.3 & 4 & 26.7 & 15 & 15 & \\
\hline & High (>4.7) & 4 & 18.2 & 18 & 81.8 & 22 & 22 & \\
\hline Total & & 59 & 59 & 41 & 41 & 100 & 100 & \\
\hline
\end{tabular}

Chi-square trend analysis.

Table 4. The distribution of rates of $C K-M B$ positivity according to N/L ratios.

\begin{tabular}{|c|c|c|c|c|c|c|c|c|}
\hline & & \multicolumn{4}{|c|}{ CK-MB } & \multicolumn{2}{|c|}{ Total } & \multirow[t]{3}{*}{$\mathbf{P}$} \\
\hline & & \multicolumn{2}{|c|}{ Negative } & \multicolumn{2}{|c|}{ Positive } & \multirow[b]{2}{*}{$\mathbf{n}$} & \multirow[b]{2}{*}{$\%$} & \\
\hline & & $\mathbf{n}$ & $\%$ & $\mathbf{n}$ & $\%$ & & & \\
\hline \multirow[t]{3}{*}{$\mathrm{N} / \mathrm{L}$ ratio } & Low $(<3.0)$ & 61 & 96.8 & 2 & 3.2 & 63 & 63 & 0.001 \\
\hline & Moderate $(3.0-4.7)$ & 13 & 86.7 & 2 & 13.3 & 15 & 15 & \\
\hline & High (>4.7) & 15 & 68.2 & 7 & 31.8 & 22 & 22 & \\
\hline Total & & 89 & 89 & 11 & 11 & 100 & 100 & \\
\hline
\end{tabular}

Chi-square trend analysis

Table 5. The distribution of rates of definitive diagnosis according to N/L ratios.

\begin{tabular}{|c|c|c|c|c|c|c|c|c|c|c|c|c|}
\hline & & \multicolumn{8}{|c|}{ Definitive diagnosis } & \multicolumn{2}{|l|}{ Total } & \multirow[t]{3}{*}{$\mathbf{p}$} \\
\hline & & \multicolumn{2}{|c|}{ Non-cardiac } & \multicolumn{2}{|c|}{ NSTEMI } & \multicolumn{2}{|c|}{ STEMI } & \multicolumn{2}{|c|}{ USAP } & \multirow[b]{2}{*}{$\mathbf{n}$} & \multirow[b]{2}{*}{$\%$} & \\
\hline & & $n$ & $\%$ & $n$ & $\%$ & $n$ & $\%$ & $n$ & $\%$ & & & \\
\hline \multirow[t]{3}{*}{$\mathrm{N} / \mathrm{L}$ ratio } & Low & 23 & 36.5 & 14 & 22.2 & 10 & 15.9 & 16 & 25.4 & 63 & 63 & \multirow[t]{3}{*}{0.034} \\
\hline & Moderate & 6 & 40 & 3 & 20 & 3 & 20 & 3 & 20 & 15 & 15 & \\
\hline & High & 5 & 22.7 & 10 & 45.5 & 7 & 31.8 & 0 & 0 & 22 & 22 & \\
\hline Total & & 34 & 34 & 27 & 27 & 20 & 20 & 19 & 19 & 100 & 100 & \\
\hline
\end{tabular}

Fisher's Exact test.

There was a difference between WBC counts according to definitive diagnosis $(\mathrm{p}<0.05)$. The Bonferroni-corrected MannWhitney U-test was performed in order to detect which group created the difference; and WBC count was found to be higher at a statistically significant level in the patients with STEMI than in the patients with USAP $(p<0.0083)$ (Table 1).

When the average distribution of $\mathrm{N} / \mathrm{L}$ ratios in the patients was examined, it was observed that $\mathrm{N} / \mathrm{L}$ ratio was found to be higher in the patients with positive troponin-I than in the patients with negative troponin-I $(\mathrm{p}<0.05)$. N/L ratio was also found to be higher in the patients with positive CK-MB than in the patients with negative CK-MB $(\mathrm{p}<0.05)$ (Table 2).

There was difference between $\mathrm{N} / \mathrm{L}$ ratios according to definitive diagnosis $(\mathrm{p}<0.05)$. In the Bonferroni-corrected Mann-Whitney U-test performed in order to detect which group created the difference, N/L ratio was found to be higher in the patients with STEMI than in the patients with USAP $(p<0.0083)$ (Table 2). 
When the distribution of rates of troponin-I positivity was examined according to $\mathrm{N} / \mathrm{L}$ ratios, it was observed that there was a relationship between the groups $(\mathrm{p}<0.05)($ As $\mathrm{N} / \mathrm{L}$ ratio increased, troponin-I positivity increased) (Table 3 ).

When the distribution of rates of CK-MB positivity was examined according to $\mathrm{N} / \mathrm{L}$ ratios, it was observed that there was a relationship between the groups $(\mathrm{p}<0.05)$ (As N/L ratio increased, CK-MB positivity increased as well) (Table 4).

When the distribution of rates of presence of additional disease and history of CAD was examined according to N/L ratios, it was observed that there was no relationship between the groups $(\mathrm{p}>0.05)$.

When the distribution of rates of definitive diagnosis was examined according to $\mathrm{N} / \mathrm{L}$ ratios, it was observed that there was a relationship between the groups $(p<0.05)$ (Table 5).

\section{Discussion}

Risk factors for CAD were first identified in the Framingham heart study, which began in 1948. The incidence and prevalence of this disease increase with age. Therefore, age can be considered as the most important risk factor [8,9].

Studies have also shown that the age limit varies between 58 and $67 \mathrm{y}$ [10-13]. The majority of the 100 patients included in our study were male (70\%, n: 70). The mean age was $57.87 \pm$ $12.85 \mathrm{y}$. This was similar to previous studies. Patients were old like in these studies.

The primary cells involved in early inflammatory response are neutrophils. The relationship between ACS, atherosclerosis, and inflammation is known. In a study of Huang et al., they evaluated the role of WBC count and its subtypes at admission in predicting major cardiac events in ACS. It was reported that the number of neutrophils was an independent marker of multivessel disease [14-19]. It was shown that $\mathrm{N} / \mathrm{L}$ ratio can be used in predicting adverse events in CAD [20,21].

In our study, the $\mathrm{N} / \mathrm{L}$ ratios were classified into 3 groups: low $(<3.0)$, moderate (3.0-4.7), and high $(>4.7)$. These values were determined on the basis of the model established by comparing the average $\mathrm{N} / \mathrm{L}$ ratios in the relevant literature [22-25]. So we used this classification.

Large and long-term studies found that the GRACE scores calculated at admission and discharge, the number of patients with TIMI 0-2 and TIMI 3-4 in the NSTEMI/USAP group, and the average TIMI scores calculated for STEMI patients were significantly different between the groups. The scores were found to be higher in groups with higher N/L ratio, and this increase was also statistically significant between the groups [26,27].

In our study, when the average distribution of $\mathrm{N} / \mathrm{L}$ ratios in the patients was examined, N/L ratio was found to be higher in the patients with positive troponin-I than in the patients with negative troponin-I, and in the patients with positive CK-MB than in the patients with negative CK-MB. In conclusion, many studies have shown that $\mathrm{N} / \mathrm{L}$ ratio, which is used for risk classification in ACS, had enough accuracy and gave better results than clinical evaluation. When taking into account the fact that there is a significant relationship between these two risk scoring systems and N/L ratios and N/L ratio is higher in patients with higher troponin levels, this supports other literature information and considerations of important authors about N/L ratio can be used as a practical risk marker in ACS. In a study of Zhan et al., N/L ratio was found highest in the STEMI group among the ACS subgroups [28].

In a study of Tamhane et al., the number of patients with elevated cardiac markers was found to be significantly higher in the group with higher N/L ratio. In a study of Azab et al., troponin levels were found to be significantly higher among the patients in the group with higher N/L ratio [26,27].

In our study, it was seen that as $\mathrm{N} / \mathrm{L}$ ratio increased, troponin positivity increased. N/L ratio was found to be higher in the patients with NSTEMI than in the patients with USAP. As a result, the detection of a statistically significant relationship between N/L ratio and $\mathrm{CK}-\mathrm{MB}$, troponin (which had been previously demonstrated for extent of myocardial injury and for cardiovascular events during follow-up) supports that $\mathrm{N} / \mathrm{L}$ ratio can be used as a risk marker in ACS together with studies having similar findings in the literature.

\section{Conclusion}

There was a positive correlation between $\mathrm{N} / \mathrm{L}$ ratio and $\mathrm{WBC}$ count, which are markers of inflammatory response during $\mathrm{ACS}$, and troponin and CK-MB, which are markers of myocardial damage. This finding suggests that N/L ratio, which is a marker of inflammatory process in the myocardial vascular bed, may be considered as a risk marker. For this reason, N/L ratio at admission can be used as an auxiliary parameter for predicting the diagnosis of ACS. Defining the role of inflammation in CHD will help us to develop new and effective ways to protect against this management of disease, which is the most important cause of death in our country as it is in the whole world.

\section{Acknowledgment}

The authors appreciate kind support of Ataturk Research and Training Hospital Katip Çelebi University, Department of Emergency Medicine, İzmir, Turkey.

\section{References}

1. British Heart Foundation. European cardiovascular disease statistics. British Heart Foundation, London 2000.

2. Gurm HS, Bhatt DL, Lincoff AM, Tcheng JE, Kereiakes DJ, Kleiman NS, Jia G, Topol EJ. Impact of preprocedural white blood cell count on long term mortality after percutaneous coronary intervention: insights from the EPIC, EPILOG, and EPISTENT trials. Heart 2003; 89: 1200-1204.

3. Horne BD, Anderson JL, John JM, Weaver A, Bair TL, Jensen KR, Renlund DG, Muhlestein JB. Intermountain 
Heart Collaborative Study Group. Which white blood cell subtypes predict increased cardiovascular risk? J Am Coll Cardiol 2005; 45: 1638-1643.

4. Zahorec R. Ratio of neutrophil to lymphocyte counts-rapid and simple parameter of systemic inflammation and stress in critically ill. Bratisl Lek Listy 2001; 102: 5-14.

5. Gibson PH, Cuthbertson BH, Croal BL, Rae D, El-Shafei $\mathrm{H}$, Gibson G. Usefulness of neutrophil/lymphocyte ratio as predictor of new-onset atrial fibrillation after coronary artery bypass grafting. Am J Cardiol 2010; 105: 186-191

6. Ross R. Atherosclerosis-an inflammatory disease. N Engl J Med 1999; 340: 115-126.

7. Palmerini T, Brener SJ, Mehran R, Dangas G, Genereux P, Riva DD. Leukocyte count is a modulating factor for the mortality benefit ofbivalirudin in ST-segment-elevation acute myocardial infarction: the HORIZONS-AMI trial. Circ Cardiovasc Interv 2013; 6: 518-526.

8. Fuster V, Hurst JW. Hurst's the heart (12th Edition). McGraw-Hill Medical 2008; 1: 35-36.

9. Scarborough P. British Heart Foundation. Coronary Heart Disease Statistic. British Heart Foundation, London 2004; $1-156$.

10. Rosengren A, Hawken S, Ounpuu S, Sliwa K, Zubaid M, Almahmeed WA. Association of psychosocial risk factors with risk of acute myocardial infarction in 11119 cases and 13648 controls from 52 countries (the inter heart study): case-control study. Lancet 2004; 364: 953-962.

11. Tello-Montoliu A, Marin F, Roldan V, Mainar L, Lopez MT, Sogorb F. A multi-marker risk stratification approach to non-ST elevation acute coronary syndrome: implications of troponin T, CRP, NT pro-BNP and fibrin D-dimer levels. $\mathrm{J}$ of Int Med 2007; 262: 651-658.

12. Macdonald SP, Nagree Y. Rapid risk stratification in suspected acute coronary syndrome using serial multiple cardiac biomarkers: a pilot study. Emerg Med Austr 2008; 20: 403-409

13. Bogaty P, Boyer L, Simard S, Dauwe F, Dupuis R, Verret B. Clinical utility of C-reactive protein measured at admission, hospital discharge, and 1 month later to predict outcome in patients with acute coronary disease. The RISCA (recurrence and inflammation in the acute coronary syndromes) study. J Am Coll Card 2008; 51: 2339-2346.

14. Huang G, Zhong XN, Zhong B, Chen YQ, Liu ZZ, Su L, Ling ZY. Significance of white blood cell count and its subtypes in patients with acute coronary syndrome. Euro J Clin Invest 2009; 39: 348-358.

15. Barron HV, Harr SD, Radford MJ, Wang Y, Krumholz HM. The association between white blood cell count and acute myocardial infarction mortality in patients $>$ or $=65$ years of age: findings from the cooperative cardiovascular project. J Am Coll Card 2001; 38: 1654-1661.

16. Barron HV, Cannon CP, Murphy SA, Braunwald E, Gibson CM. Association between white blood cell count, epicardial blood flow, myocardial perfusion, and clinical outcomes in the setting of acute myocardial infarction: a thrombolysis in myocardial infarction 10 sub study. Circulation 2000; 102: 2329-2334.

17. Kurt M, Karakas MF, Buyukkaya E, Akcay AB, Sen N. Relation of angiographic thrombus burden with electrocardiographic grade III ischemia in patients with stsegment elevation myocardial infarction. Clin App Thrombosis/Hemostasis 2013; 2: 12-15.

18. Youssef AA, Chang LT, Sheu JJ, Lee FY, Chua S, Yeh KH. Association between circulating level of CD40 ligand and angiographic morphologic features indicating high-burden thrombus formation in patients with acute myocardial infarction undergoing primary coronary intervention. Japan Circ Soc 2007; 71: 1857-1861.

19. Pellizzon GG, Dixon SR, Stone GW, Cox DA, Mattos L, Boura JA. Relation of admission white blood cell count to long-term outcomes after primary coronary angioplasty for acute myocardial infarction (The Stent PAMI Trial). Am J Card 2003; 91: 729-731.

20. Muhammed Suliman MA, Bahnacy Juma AA, Ali Almadhani AA, Pathare AV, Al kindi S, Uwe Werner F. Predictive value of neutrophil to lymphocyte ratio in outcomes of patients with acute coronary syndrome. Arch Med Res 2010; 41: 618-622.

21. Núñez J, Núñez E, Bodí V, Sanchis J, Miñana G, Mainar L, Santas E, Merlos P, Rumiz E, Darmofal H, Heatta AM, Ll Àcer A. Usefulness of the neutrophil to lymphocyte ratio in predicting long-term mortality in ST segment elevation myocardial infarction. Am J Cardiol 2008; 101: 747-752.

22. Skubitz KM. Neutrophilic leukocytes. In: Greer JP, Foerester J, Rodgers GM, Paraskevas F, Glader B, Arber DA, Means RT Jr. Wintrobe's clinical hematology. WoltersKluwer/Lippincott Williams \& Wilkins Health, Philadelphia, USA 2009; 170-193.

23. Geaghan SM. Normal blood values: selected references values for neonatal, pediatric and adult populations. Elsevier Churchill Livingstone, New York 2005.

24. Bain BJ. Ethnic and sex differences in the total and differential white cell count and platelet count. J Clin Pathol 1996; 49: 664-666.

25. Lichtman MA. Cellular deformability during maturation of the myeloblast. Possible role in marrow egress. N Engl J Med 1970; 283: 943-948.

26. Tamhane UU, Aneja S, Montgomery D, Rogers EK, Eagle KA, Gurm HS. Association between admission neutrophil to lymphocyte ratio and outcomes in patients with acute coronary syndrome. Am J Cardiol 2008; 102: 653-657.

27. Azab B, Zaher M, Weiserbs KF, Torbey E, Lacossiere K, Gaddam S. Usefulness of neutrophil to lymphocyte ratio in predicting short- and long-term mortality after non-STelevation myocardial infarction. Am J Cardiol 2010; 106: 470-476.

28. Zhan Y, Xu T, Tan X. Two parameters reflect lipid-driven inflammatory state in acute coronary syndrome: atherogenic index of plasma, neutrophil-lymphocyte ratio. BMC Cardiovasc Disord 2016; 16: 96. 


\section{*Correspondence to}

Pınar Yeşim Akyol

Department of Emergency Medicine

Izmir Katip Celebi University Ataturk Training and Research Hospital

Izmir

Turkey 